NASA Technical Memorandum 89818

\title{
Mechanical Strength and Tribological Behavior of Ion-Beam-Deposited Boron Nitride Films on Nonmetallic Substrates
}

Kazuhisa Miyoshi

Lewis Research Center

Cleveland, Ohio

Donald H. Buckley

Case Western Reserve University

Cleveland, Ohio

John J. Pouch, Samuel A. Alterovitz, and Harold $\mathrm{E}$ - Sliney

Lewis Research Center

clevetand, Onto

\section{$r$}

$-3-3,-2=-2=$

Prepared for the

International Conference on Metallurgical Coatings

sponsored by the American Vacuum Society

San Diego, California, March 23-27, 1987 
MECHANICAL STRENGTH AND TRIBOLOGICAL BEHAVIOR OF ION-BEAM-DEPOSITED BORON

NITRIDE FILMS ON NONMETALLIC SUBSTRATES*

\author{
Kazuhisa Miyoshi \\ National Aeronautics and Space Administration \\ Lewis Research Center \\ Cleveland, Ohio 44135 \\ Donald H. Buckley, \\ Case Western Reserve University \\ Cleveland, Ohio 44106
}

\author{
and \\ John J. Pouch, Samuel A. Alterovitz, and Harold E. Sliney \\ National Aeronautics and Space Administration \\ Lewis Research Center \\ Cleveland, Ohio 44135
}

\title{
SUMMARY
}

An investigation was conducted to examine the mechanical strength and tribological properties of boron nitride (BN) films ion-beam-deposited on silicon (Si), fused silica $\left(\mathrm{SHO}_{2}\right)$, gallium arsenide (GaAs), and indium phosphide (InP) substrates in sliding contact with a diamond pin under a load. The results of the investigation indicate that $B N$ films on nonmetallic substrates, like metal films on metallic substrates, deform elasticaliy and plastically in the interfacial region when in contact with a diamond pin. However, unlike metal films and substrates, BN films on nonmetallic substrates can fracture when they are critically loaded. Not only does the yield pressure (hardness) of $\mathrm{Si}$ and $\mathrm{SiO}_{2}$ substrates increase by a factor of 2 in the presence of a BN film, but the critical load needed to fracture increases as well. The presence of films on the brittle substrates can arrest crack formation. The BN film reduces adhesion and friction in the sliding contact. BN adheres to

\footnotetext{
*Trade names or manufacturers' names are used in this report for identification only. This usage does not constitute an official endorsement, either expressed or implied, by the National Aeronautics and Space Administration.
} 
Si and $\mathrm{SiO}_{2}$ and forms a good quality $\mathrm{film}$, while it adheres poorly to GaAs and InP. The interfacial adhesive strengths were 1 GPa for a BN film on Si and appreciably higher than $1 \mathrm{GPa}$ for a $\mathrm{BN}$ film on $\mathrm{SiO}_{2}$.

\section{INTRODUCTION}

Advanced propulsion systems such as gas turbines and adiabatic diesel engines are designed to achieve high efficiency through higher operating temperatures and rotational speeds $[1,2]$. These conditions lead to two primary problems. First, bearings and other load-carrying contacts are required to operate over a temperature range that exceeds the capability of conventional liquid lubricants: that is, their thermal oxidation limits $[3,4]$. None of the liquid lubricants available today are useful beyond $350^{\circ} \mathrm{C}$. Obvious candidate materials for fulfilling these needs are inorganic compounds. Indeed, conventional solid lubricants (such as $\mathrm{CaF}_{2} / \mathrm{BaF}_{2}$ binary eutectic coatings and $\mathrm{PbO} / \mathrm{SiO}_{2}$ coatings in an oxidizing atmosphere, as well as $\mathrm{MOS}_{2}$ and graphite in a nonoxidizing atmosphere) have been used at high temperatures [2]. The use of ceramics (both in bulk and coating forms) in a vacuum or space environment has tribological benefits, because of the low adhesion of ceramics in contact with themselves or with other solids such as metals [5]. Further, at high temperatures in a vacuum environment, heating a ceramic such as silicon carbide can result in the graphitization of the ceramic surface with the graphite functioning to reduce adhesion and friction. A lubricating film is, therefore, provided from the ceramic material itself $[6,7]$.

Secondly, at very high rotating speeds centrifugal forces from the rolling elements lead to extensive overload of the rotating mechanical components. One solution to this problem is to reduce the density of the material used for the rolling elements and thereby decrease the centrifugal loading. An attractive solution is to use ceramics for the rotating mechanical components [8]. For example, silicon nitride has a density approximately 40 percent that of tool 
steels; therefore, fundamental and focused research to develop high-temperature ceramics for use as components in mechanical systems is a logical approach to meet the stringent requirements of advanced engine technology.

Ion-beam-deposited boron nitride (BN) films are relatively new materials and are promising ceramics for use not only as high-temperature, wear-resistant, solid lubricating films, but also as adequate gate dielectrics for high-speed III-V semiconductor devices and integrated circuits. This is the most difficult and crucial application of an insulator film $[9,10]$.

The present work continues the ongoing tribological studies with ion-beam-deposited $B N$ films. The objectives of this study were to investigate the tribological properties and mechanical strength (interfacial adhesive and intrinsic cohesive strength) of hard and brittle BN films deposited on silicon-based nonmetallic materials. This study was initiated with wel1-defined, pure silicon (Si) and fused silica (quartz, $510_{2}$ ) substrates rather than complicated structural ceramic substrates such as silicon nitride and silicon carbide. It was aimed at gaining a more fundamental understanding of adhesion between $B N$ and sllicon-based materials.

Single-pass scratch experiments were conducted to examine the adhesion, friction, and deformation behavior of the BN films deposited on Si $\{100\}$ plane and $\mathrm{SiO}_{2}$ in sliding contact with a diamond pin in room-temperature air at a relative humidity of 45 percent. Comparative scratch experiments were also conducted with $B N$ films deposited on gallium arsenide (GaAs) and indium phosphide (InP) $\{100\}$ planes sliding in the $\langle 110\rangle$ directions.

\section{MATERIALS}

Thin films containing $B N$ have been synthesized by Spire corporation using an ion beam extracted from a borazine $\left(\mathrm{B}_{3} \mathrm{~N}_{3} \mathrm{H}_{6}\right)$ plasma [11]. The substrates used for scratch experiments were $\mathrm{Si}_{1} \mathrm{SiO}_{2}$, GaAs, and InP ( Table I). 
APPARATUS

The ion source used to deposit $B N$ films is described in reference 11 .

The friction and wear apparatus used in this investigation was capable of scratching the surface of a BN film with a rounded diamond pin (a Rockwell cone diamond with a tip radius of $0.2 \mathrm{~mm}$ ). The apparatus was the Revetest, a commercially purchased device [12-14]. A load was applied by placing deadweights on a pan on top of a rod. The other end of the rod contained the diamond pin. A piezoelectric accelerometer mounted just above the diamond pin detected the acoustic emission released as the coating film was disturbed.

XPS and AES/SIMS systems were also used for chemical composition analyses of the BN films.

\section{EXPERIMENTAL PROCEDURE}

The experiments were conducted in a laboratory air atmosphere. The diamond pin surfaces were scrubbed with levigated alumina (1-and 1/4- $\mu \mathrm{m}$ particle diameters) and were rinsed with tap water, then with distilled water, and finally with 200-proof ethyl alcohol before each single-pass sliding experiment. The $B N$ films were also rinsed with 200-proof ethyl alcohol before use. After the surfaces of the pin and the $B N$ film had been dried with nitrogen gas, the specimens were placed in the friction and wear apparatus. The specimen surfaces were then brought into contact and loaded, and the friction experiment was begun. The time in contact before sliding was $30 \mathrm{sec}$. Each sliding experiment consisted of a single pass with a total sliding distance of approximately $10 \mathrm{~mm}$ at a sliding velocity of $12 \mathrm{~mm} / \mathrm{min}$. The acoustic emission signal was continuously monitored during sliding, and the wear tracks formed on the $\mathrm{BN}$ fllms were examined by scanning electron and optical microscopes. 


\section{RESULTS AND DISCUSSION}

Microstructure and Chemical Composition

It was found that the ion-beam-deposited BN films were predominantiy amorphous. In addition to a structureless amorphous phase, however, there was a crystalline phase with a size range of 8 to $30 \mathrm{~nm}$. That is, the films were not completely amorphous; properties characteristic of hexagonal $\mathrm{BN}$ were detected. This finding agrees with electron microscopy and optical band gap observations $[3,4,15]$.

The XPS and AES/SIM analyses revealed that the BN films were nonstoichiometric, with a $B / N$ ratio of approximately 2 , and that they contained small amounts of oxides and carbides in addition to $B N[3,4,5,15]$.

Friction and Wear

When a diamond hemisphere slides on a BN film deposited on a nonmetalilic substrate, the surface damage is indicated in two main features. First, the diamond indents and slides on the BN film without itself suffering permanent deformation, but it causes permanent deformation in the BN film - the scratch has the typical grooved appearance characteristic of metals or other ductile materials. Secondly, in spite of this gross plastic deformation, the sliding action also produces visible microscopic cracking of the $B N$ film and the substrate. Microscopic fragmentation of the $B N$ film is occasionally observed in and near the region of contact with the diamond.

Acoustic emissions were released and detected when the intrinsic cohesive bonds in the $B N$ film and/or in the substrate, as well as adhesive bonds between the $B N$ f $11 \mathrm{~m}$ and the substrate, were broken with a new surface being created. The pattern and intensity of the acoustic emission depend on the nature of the disturbance: plastic flow, cracking, or flaking of fragments. 
Figure 1 presents typical acoustic emission traces for a BN film deposited on a nonmetalific substrate. When the $B N$ film surface is brought into contact with the diamond pin under a small load, which is lower than the critical loads needed to fracture intrinsic cohesive bonds in the $B N$ film on the substrate (Table II), no acoustic emission is detected (Fig. T(a)). After the diamond had passed over the surface only once, scanning electron microscopic examination of the wear track indicated that a permanent groove was formed in the BN film, much like in metallic films under simflar conditions [16], However, the BN film was not observed to crack with sliding. An increase in load to or above the critical loads needed to fracture the intrinsic cohesive bonds in the $B N$ film and in the substrate, however, resulted in a small amount of cracking in and near the plastically deformed groove. The acoustic emission trace indicated evidence of a fluctuating acoustic emission signal output (fig. $T($ b)). Acoustic emission was observed when the sliding appeared to involve small amounts of cracking in addition to plastic flow. Such acoustic emission is due to the release of elastic energy when cracks propagate in the BN film and in the substrate.

When a much higher load was applied to the BN fllm, the sliding action produced (in addition to plastic flow) locally gross surface and subsurface fracturing in the film, in the substrate, and at the interface between the $B N$ film and the substrate. In such cases the acoustic emission traces are primarily characterized by chevron-shaped behavior (fig. I(c)).

$$
\text { Coefficient of Friction }
$$

The coefficients of friction measured in laboratory air for BN films on the Si, $\mathrm{SiO}_{2}$, GaAs, and InP substrates are presented in Fig. 2, together with comparative data for uncoated Si, $\mathrm{SiO}_{2}, \mathrm{GaAs}$, and InP. The coefficients of friction depend on the type of nonmetallic substrate on which the BN was deposited as well as on the applied normal load. 
The coefficient of friction ts lowest with BN films deposited on Si and $\mathrm{SiO}_{2}$ substrates at temperatures of 200 and $350{ }^{\circ} \mathrm{C}$. Good quality films were obtained on $\mathrm{Si}$ and $\mathrm{SiO}_{2}$ substrates at these deposition temperatures.

The coefficients of friction for BN films on doped GaAs and $S n$-doped InP substrates are relatively higher and are almost the same as those for the uncoated surfaces of GaAs and InP substrates (Figs. $2(c)$ and (d)). Optical microscopic examination of the wear tracks on the BN films deposited on doped GaAs and InP substrates clearly revealed that the sliding action caused breakthrough of the film in the contact area.

The breakthrough of the BN films is due to poor interfacial adhesive bonds existing between the $f 11 \mathrm{~m}$ and the substrate in and near the diamond contact region. The removal of the $B N$ films induced direct contact of the diamond pin with the doped GaAs and InP substrates. It, therefore, resulted in a higher coefficient of friction.

The BN film adhered poorly to the undoped InP substrate (Fig. $2(d)$ ). However, it did provide relatively lower coefficients of friction than were obtained for uncoated InP. Optical microscopic examination of the wear tracks of the $B N$ flim deposited on the undoped InP clearly revealed that the sliding action of the diamond burnished the $B N$ film to the substrate. When this occurs, the diamond does not entirely break through the $B N$ film in the contact area and does not come in direct contact with the undoped InP substrate. The coefficient of friction is not constant and depends on the applied normal load in the ranges indicated in Fig. 2 .

There are generally three main observations to be made from the data. First, below a certain load, depending on the substrate, the coefficient of friction decreases steadily as the load is increased. The sliding action with the diamond on the $B N$ film produces predominantly elastic deformation accompanied by a permanent groove. The real area of contact, therefore, is 
not generally proportional to the load, and there is a corresponding deviation from Amontons' Law. For a first approximation for the load range investigated, the relation between coefficient of friction $\mu$ and load $W$ is given by $\mu=\mathrm{KW}^{1 / 3}[17,18]$. The friction is a function of the shear strength of the elastic contact area.

Second, at higher loads, the friction behavior is modified. There is a very small but definite increase in coefficient of friction corresponding to the increased amount of mean yield pressure $P_{m}$ in the contact area. The wear track generally consists of plastic deformation and slight cracking of the BN film and substrate. At higher loads, the increase in coefficient of friction with load is due mainly to plastic grooving. This is in direct contrast to the decrease in coefficient of friction with load observed at small loads. The plowing process, which generates plastic grooves and cracking in the $B N$ film, absorbs an additional amount of frictional energy.

Third, with the BN film on Te-doped GaAs, with the BN film on Sn-doped InP, and with the uncoated InP (Figs. $2(c)$ and (d)), the coefficient of friction increased drastically above a specific load depending on the material. The sliding action with these surfaces produces catastrophic gross surface and subsurface fracturing as well as plastic deformation. Under such conditions wear debris particles and large fracture pits were observed. The area of the fracture pit was a few times larger than that of the plastically deformed groove.

The drastic increase in friction is due to the catastrophic gross surface and subsurface fracturing of the $B N$ film and the substrate. Most of the frictional energy is dissipated in the fracturing process during sliding. 
Yield Pressure and Meyer's Law

Scratch measurements were conducted with a $B N$ f $11 \mathrm{~m}$ deposited on the substrates, starting from the smallest loads at which the scratches were visible by optical and scanning electron microscopy.

The width $D$ and height $H$ of a groove with some amount of deformed $B N$ piled up along its sides are defined in Fig. 3. The widths of the grooves reported herein were obtained by averaging the widths from 10 or more measurements of optical or scanning-electron microscope observations. Mean contact pressure (yield pressure) $P$ during sliding may then be defined by $P=W / A_{S}$, where $W$ is the applied load and $A_{S}$ is the projected contact area given by $A_{S}=\pi D^{2} / 8$ (only the front half of the pin is in contact with the flat) $[15,19]$.

The yield pressure over the contact area gradually increased until the deformation passed to a fully plastic state, as presented in Figs. $4(a)$ to (d). The mean contact pressure at a fully plastic state $P_{m}$ is proportional to and approximately 25 percent greater than the measured vickers hardness (Tables II and III).

The yield pressure of $\mathrm{Si}$ and $\mathrm{StO}_{2}$ increased by a factor of 2 with the presence of $B N$ films (figs. $4(a)$ and (b)). When the load exceeds a certain critical value (Fig. $4(a)$ ), the sliding action with the diamond on the BN film deposited on si produces locally gross surface and subsurface fracturing in the $B N$ film and in the Si substrate. The portion FF in Fig. 4(a) represents the condition of severe fracture, and the yield pressure falls with increasing load.

There was no gross fallure of interfacial adhesive bonds between the $B N$ f $\left\{1 \mathrm{~m}\right.$ and the $\mathrm{SiO}_{2}$ substrate observed over the entire load range (Fig. $4(\mathrm{~b})$ ). Therefore, the yield pressure at the fully plastic state remained constant. 
The yield pressures for BN films on doped GaAs and on InP are the same as those for the uncoated surfaces of doped GaAs and InP (Figs. 4(c) and (d)). The BN films adhered poorly to the GaAs and InP substrates, and the breakthrough and removal of the $\mathrm{BN}$ films induced direct contact of the diamond pin with the doped GaAs and InP substrates, as described earlier. Therefore, the yield pressure of the doped GaAs and InP did not increase with the presence of $\mathrm{BN}$ films.

The relation between the load and the width of the resulting scratch may be expressed with a number derived from empirical relations [20]. When the width of the resulting scratch $D$ for BN films is plotted against the load $W$ on logarithmic coordinates, this is expressed as $w=k D^{n}$ (1.e., Meyer's law, as typically presented in Fig. 5.).

Figures $5(a)$ to (d) present data for scratch widths obtained for BN films on $\mathrm{Si}, \mathrm{SHO}_{2}, \mathrm{GaAs}$, and InP substrates. Comparative data for uncoated $\mathrm{Si}$, $\mathrm{SiO}_{2}$, GaAs, and InP are also presented. The portion LM for BN films or $L ' M '$ for uncoated matertals is gradually curved but is considered to be composed of approximately straight portions of transitional slopes. For example, the transitional slopes are 2.6 and 2.4 for the BN film on Si. The portion MN for BN films, or $M^{\prime} N^{\prime}$ for uncoated materials, is a straight line with a slope of 2 . It is evident that either $M N$ or $M^{\prime} N^{\prime}$ is the range over which Meyer's law is valid for BN films on nonmetallic substrates and for uncoated nonmetallic materials. Here the Meyer's index $n$ is a constant and has a value of 2 . Thus, the $B N$ films on nonmetallic substrates behave plastically much like metals when they are brought into contact with hard solids, such as diamond. 
Adhesion and Shear Strength

Silicon. - With uncoated Si (Table III), the critical load to fracture cohesive bonds in the Si was $5 \mathrm{~N}$ in sliding contact. With the BN film deposited on the Si substrate, however, cracking occurred at a load of $7 \mathrm{~N}$ (Table II). The BN film on the Si plays an important role in surface fracture. The presence of $B N$ film is very effective in increasing the critical load needed to initiate fracture in Si. A similar trend was observed with good quality $\mathrm{BN}$ films on $\mathrm{SiO}_{2}$, as well as with poorly adhered films on $\mathrm{Zn-doped}$ GaAs and undoped InP (Tables II and III).

The failure of the $B N$ film on the Si substrate did not induce fracture of interfacial adhesive bonds between the $B N$ film and the substrate. The critical loads to fracture the interfacial adhesive bonds were $11 \mathrm{~N}$ for the $\mathrm{BN}$ film deposited on $\mathrm{Si}$ at $200^{\circ} \mathrm{C}$ and $8 \mathrm{~N}$ for that at $350{ }^{\circ} \mathrm{C}$ (Table IV).

Benjamin and Weaver [21] derived the following expressions for scratch adhesion in terms of shearing stress $S$ produced at the coating-substrate interface by the plastic deformation, the hardness of the substrate (yieid pressure at fully plastic state $P_{m}$ ), the critical load applied on the pin $W_{C}$, and the tip radius of the pin $R$ :

$$
\begin{gathered}
S=K\left(\frac{W_{C} P_{m}}{\pi R^{2}}\right)^{1 / 2} \\
S \simeq \frac{2 W_{c}}{\pi D R}
\end{gathered}
$$

These relations allow for the calculation of the shear strength (i.e., the adhesion strength of the interfacial bonds) $[19,21]$. The results are presented in Table IV. The values of the critical loads were obtained and confirmed not only by optical and SEM microscopy of the scratches, but also by the acoustic emission technique. 
Fused Silica. - Hertzian cracks were developed in the BN film deposited on $\mathrm{SiO}_{2}$ as well as in the uncoated $\mathrm{SHO}_{2}$ at the specific loads indicated in Tables II and III, respectively. The diamond traversing a BN flim surface generated intermittent, circular hertzian cracks in the BN film and in the $\mathrm{SiO}_{2}$ substrate just outside the mutual contact zone between the loaded diamond and $B N$ film. The cracks intersected each other during sliding.

Although very local detachment of the $B N$ film was observed in areas where the cracks intersected, no gross fallure of interfacial adhesive bonds between the $\mathrm{BN}$ film and the $\mathrm{SiO}_{2}$ substrate was observed, even at loads to $15 \mathrm{~N}$. Therefore, the actual value of the interfacial adhesive strength between the BN film and $\mathrm{SiO}_{2}$ substrate is larger than those for the BN film on the Si substrate indicated in Table IV. This relative high adhesion is attributable to the strong chemical bond formed between $\mathrm{BN}$ and $\mathrm{SiO}_{2}$.

CONCLUSIONS

As a result of single-pass scratch experiments conducted with ion-beam-deposited boron nitride (BN) films on silicon (Si), fused silica $\left(\mathrm{SiO}_{2}\right)$, gallium arsenide (GaAs), and indium phosphide (InP) substrates in sliding contact with a diamond pin, the following conclusions were drawn:

1. BN films and nonmetallic substrates, like metal films and substrates, deform elastically and plastically in the interfactal region between two solids in contact under a load. However, unlike metallic fllms and substrates, BN films and nonmetaliic substrates can fracture when they are critically loaded.

2. Not only the yield pressure (hardness) of $\mathrm{Si}$ and $\mathrm{SIO}_{2}$ increased by a factor of 2 with BN films, but the critical load needed to fracture these materials also increased. The $B N$ films arrested crack formation.

3. The $B N$ films reduced adhesion and friction in sliding contact. The coefficients of friction for $\mathrm{BN}$ films on $\mathrm{Si}$ and $\mathrm{SiO}_{2}$ were less than 0.1 when sliding against diamond. 
4. $\mathrm{BN}$ adhered to $\mathrm{Si}$ and $\mathrm{SiO}_{2}$ and formed good quality films, but it adhered poorly to GaAs and InP. The interfacial adhesive strengths were $1 \mathrm{GPa}$ for BN film on Si and appreciably higher than 1 GPa for $\mathrm{BN}$ film on $\mathrm{SiO}_{2}$.

5. The relation between the load $W$ and the width of the plasticaliy deformed groove $D$ for $B N$ films is expressed by $W=K D^{n}$ (1.e., the classical Meyer's law).

6. Acoustical measurements of the critical load required to fracture a $B N$ film on a nonmetaliic substrate agree well with those detected by optical and SEM microscopy of the scratches.

\section{REFERENCES}

1. H.E. Sliney, T.P. Jacobson, D. Deadmore, and K. Miyoshi, Ceram. Eng. Sci. Proc., I (1986) 1039 .

2. H.E. Sliney, in Solid and Liquid Lubricants for Extreme Environments, American Society of Lubrication Engineers, Park Ridge, I11inois, 1984, pp. $1-6$.

3. W.R. Loomis, in Solid and Liquid Lubricants for Extreme Environments, American Soctety of Lubrication Engineers, Park Ridge, Illinois, 1984, pp. $33-39$.

4. L.D. Wedeven, R.A. Pallini, and B.B. Aggarwal, in Proceedings of the Twenty-Third Automotive Technology Development Contractors' Coordination Meeting, Society of Automotive Engineers, Warrendale, PA, 1986, pp. 99-116.

5. K. Miyoshi, D.H. Buckley, and T. Spalvins, J. Vac. Sci. Technol. A., $\underline{3}$ (1985) 2340.

6. K. Miyoshi and D.H. Buckley, Appl. Surf. Sc1., 10 (1982) 357.

7. K. Miyoshi and D.H. Buckley, Ceram. Eng. Sct. Proc., 4, (1983) 674.

8. R.N. Katz and J.G. Hannoosh, Int. J. High Technol. Ceram., 1 (1985) 69. 
9. J.J. Pouch, S.A. Alterovitz, and J.D. Warner, Auger Electron Spectroscopy, Secondary Ion Mass Spectrometry and Optical Characterization of a-C:H and BN Films, NASA TM-87258, 1986.

10. S.A. Alterovitz, J.D. Warner, D.C. Liu, and J.J. Pouch, in V.J. Kapoor, D.J. Connolly, and Y.H. Wong (eds.), Dielectric Films on Compound Semiconductors, Electrochemical Society, Pennington, New Jersey, 1986, pp. 59-77.

11. S. Shanfield and R. Wolfson, J. Vac. Sci. Technol. A., I (1983) 323.

12. P. Laeng and P.A. Steinmann, in J.M. Blocher Jr., G.E. Voillard, and G. Wahl (eds.), Proceedings of the Eighth International Conference on Vapor Deposition. Electrochemical Society, Pennington, New Jersey, 1981 , pp. $723-736$.

13. H.E. Hintermann, in R.K. Viswanadham, D.J. Rowcliffe, and J. Gorland (eds.), Science of Hard Materials, Plenum, New York, 1983, Pp. 357-394.

14. P.A. Steinmann and H.E. Hintermann, J. Vac. Sci. Technol. A., $\underline{3}$ (1985) 2394 .

15. K. Miyoshi, D.H. Buckley, S.A. Alterovitz, J.J. Pouch, and D.C. Liu, Adhesion, Friction, and Deformation of Ion-Beam-Deposited Boron Nitride Films, NASA TM-88902, 1987.

16. K. Miyoshi, T. Spalvins, and D.H. Buckley, Wear, 108 (1986) 169.

17. F.P. Bowden and D. Tabor, in The Friction and Lubrication of Solids, Part II. Clarendon Press, 0xford, 1964, pp. 159-185.

18. K. Miyoshi and D.H. Buckley, ASLE Trans., 22 (1979) 79.

19. J. Ahn, K.L. Mittal, and R.H. Macqueen, in K.L. Mittal (ed.), Adhesion Measurements of Thin Films, Thick Films, and Bulk Coatings, ASTM, Philadelphia, 1978, pp. 134-157.

20. D. Tabor, The Hardness of Metals, Clarendon Press, Oxford, 1951.

21. P. Benjamin and C. Weaver, Proc. R. Soc. London A, 254 (1960) 163. 
TABLE I. - SUBSTRATES

\begin{tabular}{|c|c|c|c|c|c|c|}
\hline \multirow[t]{2}{*}{ Material } & \multicolumn{2}{|c|}{ Doping } & \multirow{2}{*}{$\begin{array}{c}\text { Resistivity, } \\
\Omega-\mathrm{cm}\end{array}$} & \multicolumn{2}{|c|}{ Sliding } & \multirow{2}{*}{$\begin{array}{l}\text { Primary } \\
\text { cleavage } \\
\text { plane }\end{array}$} \\
\hline & Dopant & $\begin{array}{c}\text { Concen- } \\
\text { tration, } \\
\mathrm{cm}^{-3}\end{array}$ & & Plane & Direction & \\
\hline Si & - & $\ldots-\cdots$ & 0.01 to 0.02 & $\{100\}$ & $\langle 110\rangle$ & $\{111\}$ \\
\hline $\mathrm{SiO}_{2}$ (quartz) & - & $--\cdots$ & 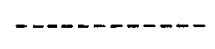 & $-\cdots-$ & $\cdots$ & $-\cdots-$ \\
\hline p-type GaAs & $\mathrm{Zn}$ & $3 \times 10^{17}$ & 0.12 & $\{100\}$ & $\langle 110\rangle$ & $\{110\}$ \\
\hline n-type GaAs & Te & $3 \times 10^{17}$ & - - - & $\{100\}$ & $\langle 110\rangle$ & $\{110\}$ \\
\hline InP & -- & $---\ldots$ & - - - & $\{100\}$ & $\langle 110\rangle$ & $\{110\}$ \\
\hline n-type InP & Sn & $3 \times 10^{17}$ & 0.010 & $\{100\}$ & $\langle 110\rangle$ & $\{110\}$ \\
\hline
\end{tabular}

TABLE II. - YIELD PRESSURE OF AND CRITICAL NORMAL LOAD TO FRACTURE BORON NITRIDE FILM COATED ON

NONMETALLIC SUBSTRATE

\begin{tabular}{|c|c|c|c|c|}
\hline $\begin{array}{c}\text { Substrate } \\
\text { and } \\
\text { f } 11 \mathrm{~m}\end{array}$ & $\begin{array}{c}\text { Yieid } \\
\text { pressure } \\
\text { at fully } \\
\text { plastic } \\
\text { state } \\
\text { Pm, } \\
\text { GPa }\end{array}$ & $\begin{array}{c}\text { Vickers } \\
\text { hardness } \\
\mathrm{H}_{\mathrm{V}}, \\
\text { GPa }\end{array}$ & $\begin{array}{l}\text { Rat10 } \\
P_{m} / H_{v}\end{array}$ & $\begin{array}{c}\text { Critical } \\
\text { normal } \\
\text { load to } \\
\text { fracture, } \\
N\end{array}$ \\
\hline $\begin{array}{l}\text { Si coated with } \\
\text { BN at } 200{ }^{\circ} \mathrm{C}\end{array}$ & 24.0 & 18.8 & 1.28 & 7 \\
\hline $\begin{array}{l}\text { Si coated with } \\
\mathrm{BN} \text { at } 350^{\circ} \mathrm{C}\end{array}$ & 21.9 & 17.5 & 1.25 & 7 \\
\hline $\begin{array}{l}\mathrm{SiO}_{2} \text { coated with } \\
\mathrm{BN} \text { at } 200{ }^{\circ} \mathrm{C}\end{array}$ & 23.9 & --- & ---- & 3 \\
\hline $\begin{array}{l}\mathrm{SiO}_{2} \text { coated with } \\
\mathrm{BN} \text { at } 3500^{\circ} \mathrm{C}\end{array}$ & 21.2 & 17.2 & 1.23 & 3 \\
\hline $\begin{array}{l}\text { Zn-doped, } \\
\text { p-type GaAs } \\
\text { coated with BN }\end{array}$ & 7.15 & 5.72 & 1.25 & 3 \\
\hline $\begin{array}{l}\text { Te-doped, } \\
\text { n-type GaAs } \\
\text { coated with BN }\end{array}$ & 7.05 & 5.65 & 1.25 & 3 \\
\hline $\begin{array}{c}\text { InP coated } \\
\text { with } B N\end{array}$ & 4.51 & 3.66 & 1.23 & 2 \\
\hline $\begin{array}{l}\text { Sn-doped, } \\
\text { n-type InP } \\
\text { coated with BN }\end{array}$ & 4.54 & 3.61 & 1.26 & 1 \\
\hline
\end{tabular}


TABLE III. - YIELD PRESSURE OF ANO CRITICAL NORMAL LOAD TO FRACTURE NONMETALLIC MATERIALS

\begin{tabular}{|c|c|c|c|c|}
\hline Material & $\begin{array}{c}\text { Yield } \\
\text { pressure } \\
\text { at fully } \\
\text { plastic } \\
\text { state } \\
\text { Pm. } \\
\text { GPa }\end{array}$ & $\begin{array}{c}\text { Vickers } \\
\text { hardness } \\
H_{v}, \\
\text { GPa }\end{array}$ & $\begin{array}{l}\text { Ratio } \\
\mathrm{P}_{\mathrm{m}} / \mathrm{H}_{\mathrm{v}}\end{array}$ & $\begin{array}{c}\text { Critical } \\
\text { normal } \\
\text { load to } \\
\text { fracture, } \\
\mathrm{N}\end{array}$ \\
\hline Si & 12.6 & 9.89 & 1.27 & 5 \\
\hline $\mathrm{SiO}_{2}$ & 12.4 & $-\cdots$ & $\ldots$ & 1 \\
\hline $\begin{array}{l}\text { Zn-doped, } \\
\text { p-type GaAs }\end{array}$ & 6.94 & 5.61 & 1.24 & 2 \\
\hline $\begin{array}{l}\text { Te-doped, } \\
\text { n-type GaAs }\end{array}$ & -..- & 5.68 & $-\cdots$ & - \\
\hline In $P$ & --- & -..- & --- & 1 \\
\hline $\begin{array}{l}\text { Sn-doped, } \\
\text { n-type InP }\end{array}$ & 4.35 & 3.49 & 1.25 & 1 \\
\hline
\end{tabular}

TABLE IV. - CRITICAL NORMAL LOAD TO FRACTURE INTERFACIAL ADHESIVE BONDS BETWEEN BN FILM AND SILICON SUBSTRATE AND SHEAR STRENGTH OF INTERFACIAL ADHESIVE BONDS

\begin{tabular}{|c|c|c|c|}
\hline \multirow[t]{2}{*}{$\begin{array}{l}\text { Coating } \\
\text { conditiona }\end{array}$} & \multirow{2}{*}{$\begin{array}{c}\text { Critical } \\
\text { normal } \\
\text { load, } \\
W_{C} \text {. } \\
N\end{array}$} & \multicolumn{2}{|c|}{$\begin{array}{c}\text { Interfacial adhesive strength, } \\
\text { S, } \\
\text { GPa }\end{array}$} \\
\hline & & $\begin{array}{l}\text { S obtained } \\
\text { from eq. (1) }\end{array}$ & $\begin{array}{l}\text { S obtained } \\
\text { from eq. (2) }\end{array}$ \\
\hline $200^{\circ} \mathrm{C}$ & 11 & 1.1 & 1.0 \\
\hline $350^{\circ} \mathrm{C}$ & 8 & .91 & .84 \\
\hline
\end{tabular}

a Nominal temperature of substrate during lon-beam deposition. 


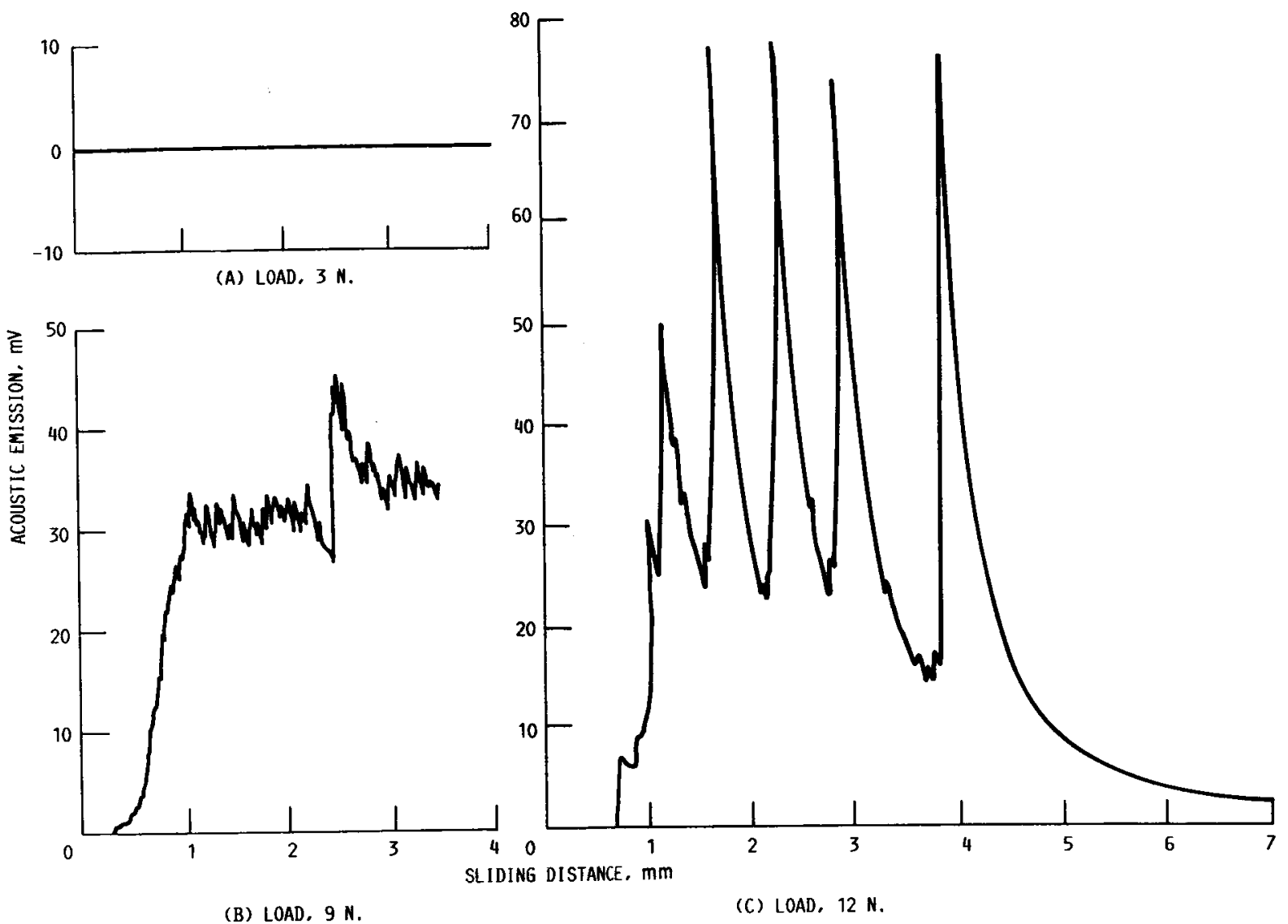

(B) LOAD, $9 \mathrm{~N}$.

(C) LOAD, $12 \mathrm{~N}$

FIGURE 1. - TYPICAL ACOUSTIC EMISSION TRACES FOR A BN FILM ON A NONMETALLIC MATERIAL (SUBSTRATE. $\mathrm{Si}$; SLIDING VELOCITY, $12 \mathrm{~mm} / \mathrm{min}$; LABORATORY AIR). 


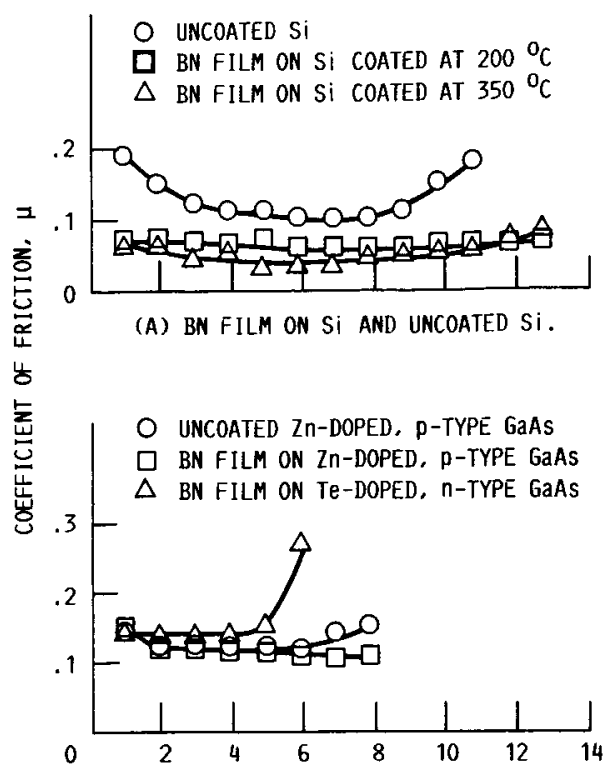

(C) BN FILM ON GaAs AND UNCOATED GaAs.

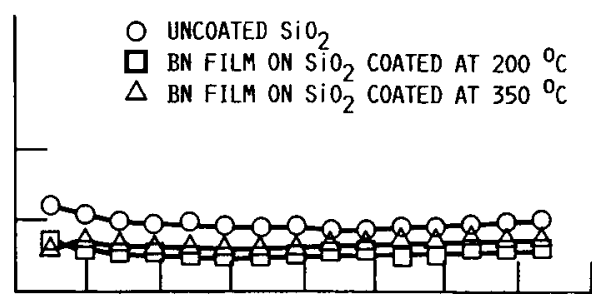

(B) BN FILM ON $\mathrm{SiO}_{2}$ AND UNCOATED $\mathrm{SiO}_{2}$.

O UNCOATED InP

G BN FILM ON UNDOPED INP

$\triangle$ BN FILM ON Sn-DOPED, $n$-TYPE INP

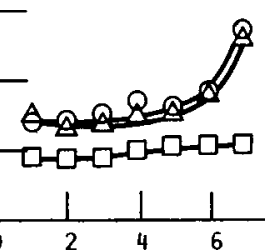

OAD, W, N

(D) BN FILM ON INP AND UNCOATED INP.

FIGURE 2. - COEFFICIENT OF FRICTION AS A FUNCTION OF LOAD. SLIDING VELOCITY, $12 \mathrm{~mm} / \mathrm{min}$ LABORATORY AIR.
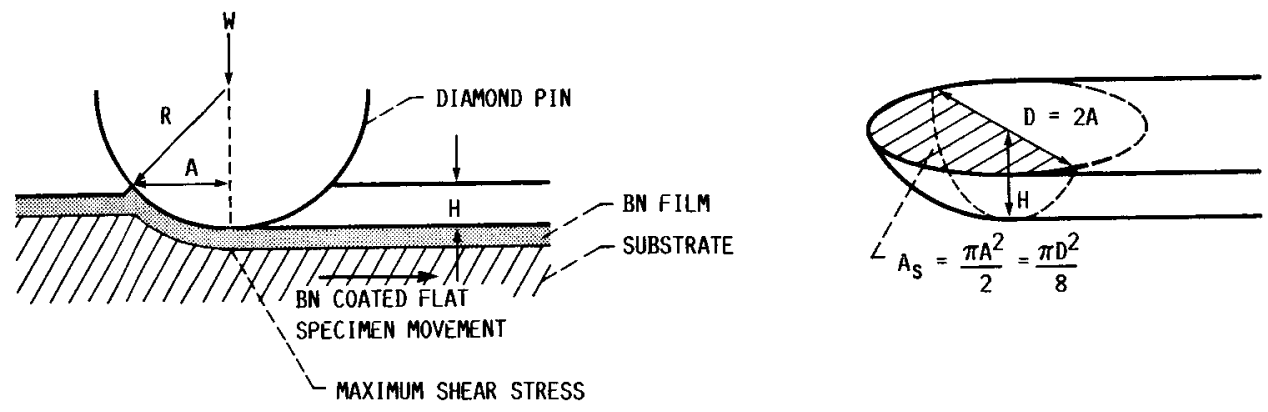

FIGURE 3. - DEFINITION OF MEAN CONTACT PRESSURE $(P=$ W/A $S$ ), OR SCRATCH HARDNESS. 

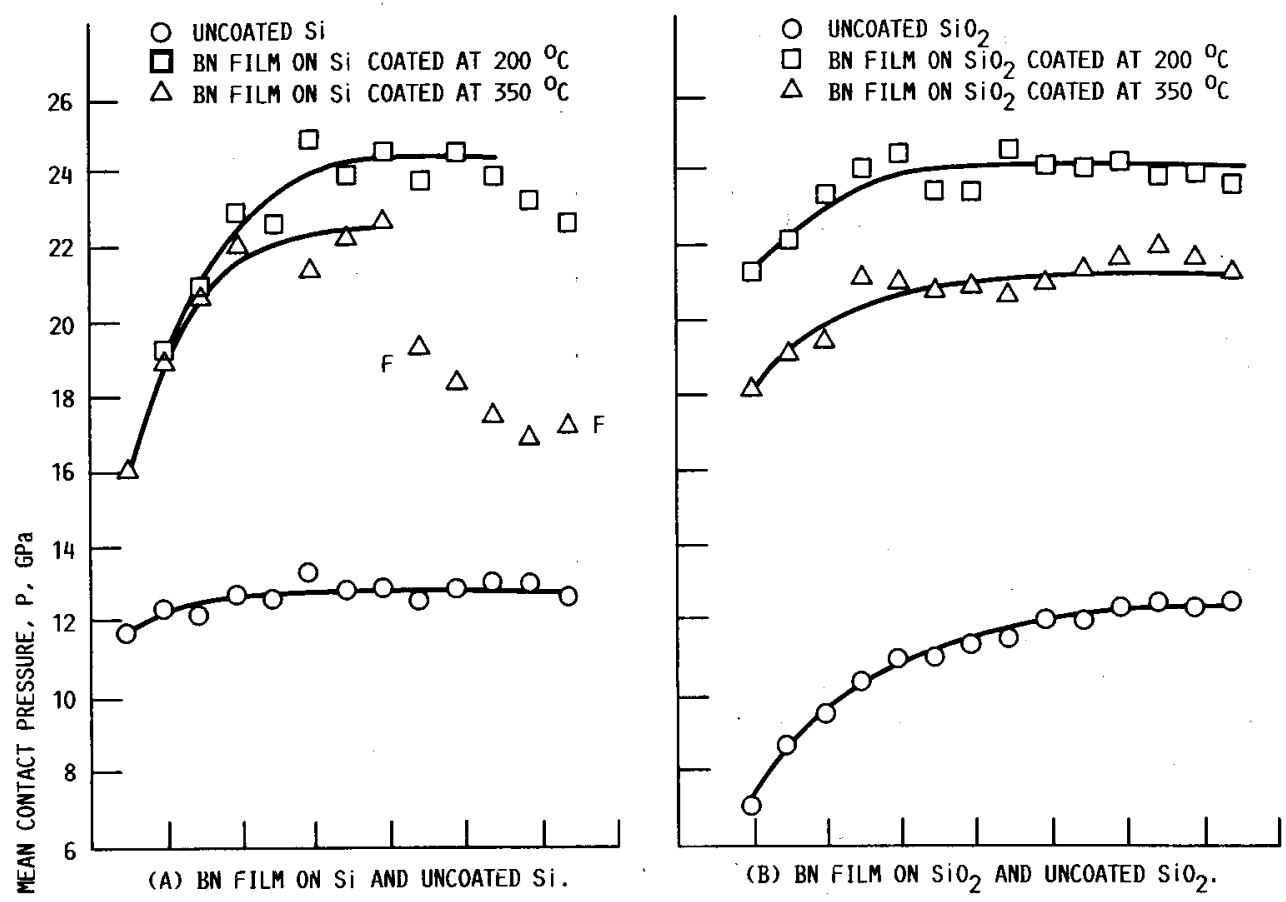

(B) BN FILM ON $\mathrm{SiO}_{2}$ AND UNCOATED $\mathrm{SiO}_{2}$.
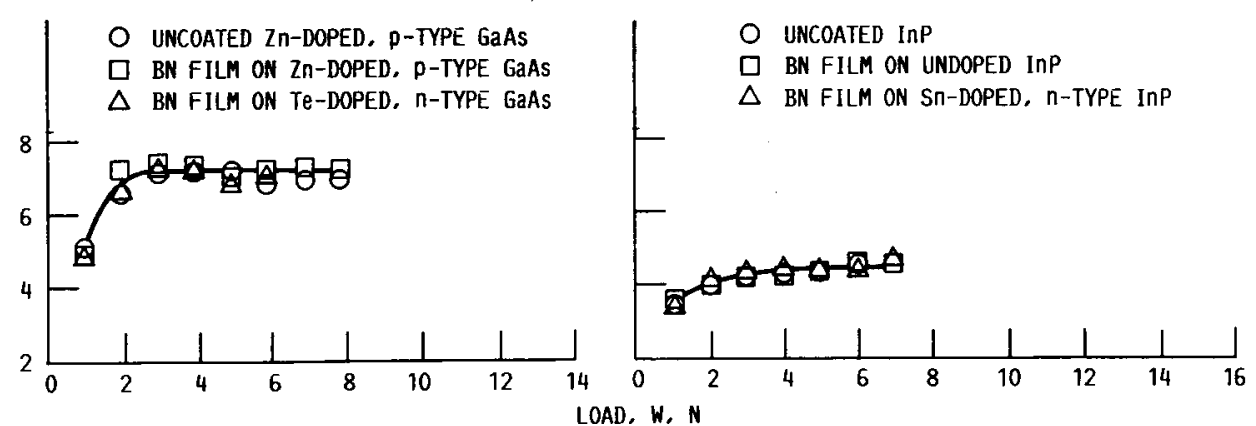

(C) BN FILM ON GaAS AND UNCOATED GaAs.

(D) BN FILM ON InP AND UNCOATED INP.

FIGURE 4. - MEAN CONTACT PRESSURE (YIELD PRESSURE) AS A FUNCTION OF LOAD. SLIDING VELOCITY, $12 \mathrm{~mm} / \mathrm{min}$; LABORATORY AIR. 


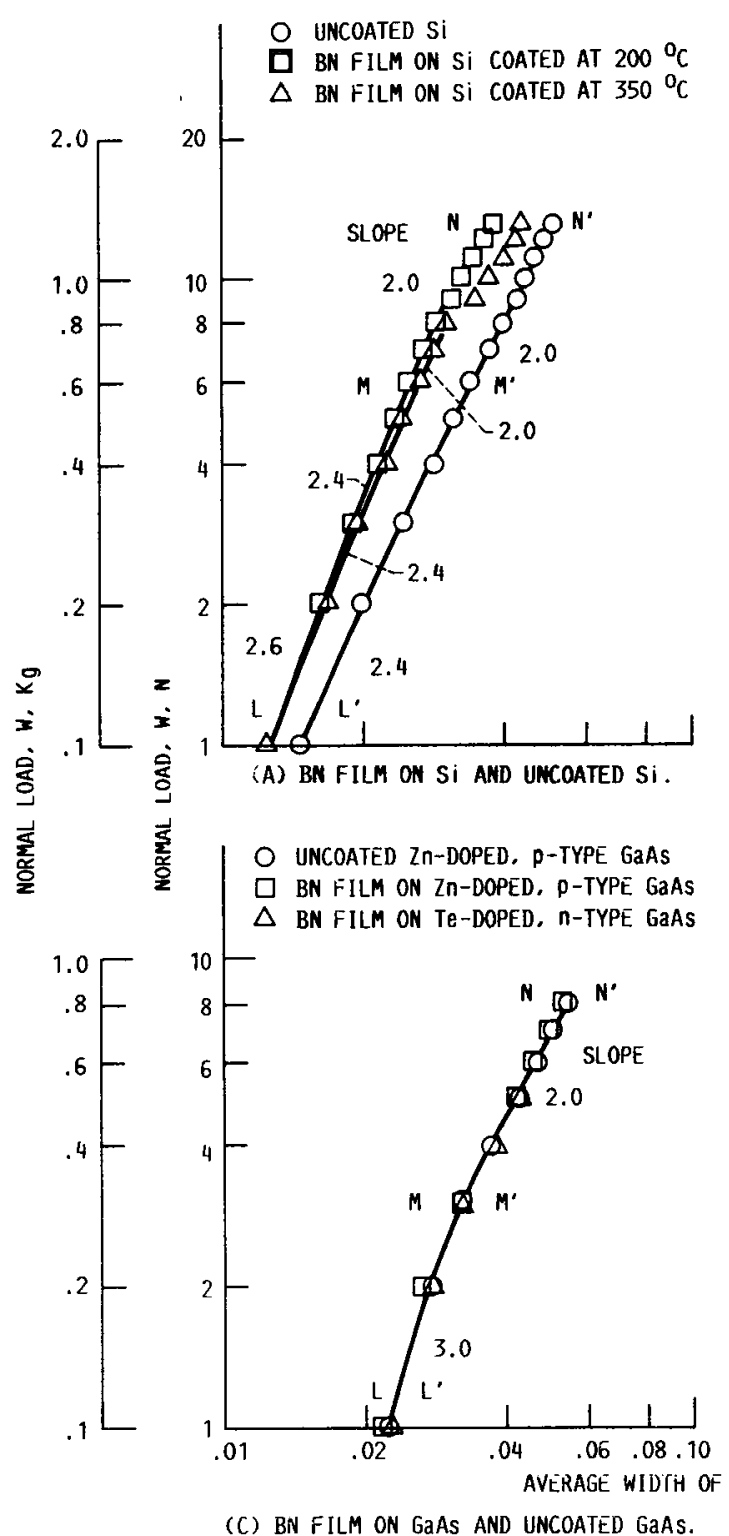

$\mid \begin{array}{ll}O & \text { UNCOATED } \mathrm{SiO}_{2} \\ \square & \text { BN FILM ON } \mathrm{SiO}_{2} \text { COATED AT } 200{ }^{\circ} \mathrm{C} \\ \triangle & \text { BN FILM ON } \mathrm{SiO}_{2} \text { COATED AT } 350^{\circ} \mathrm{C}\end{array}$
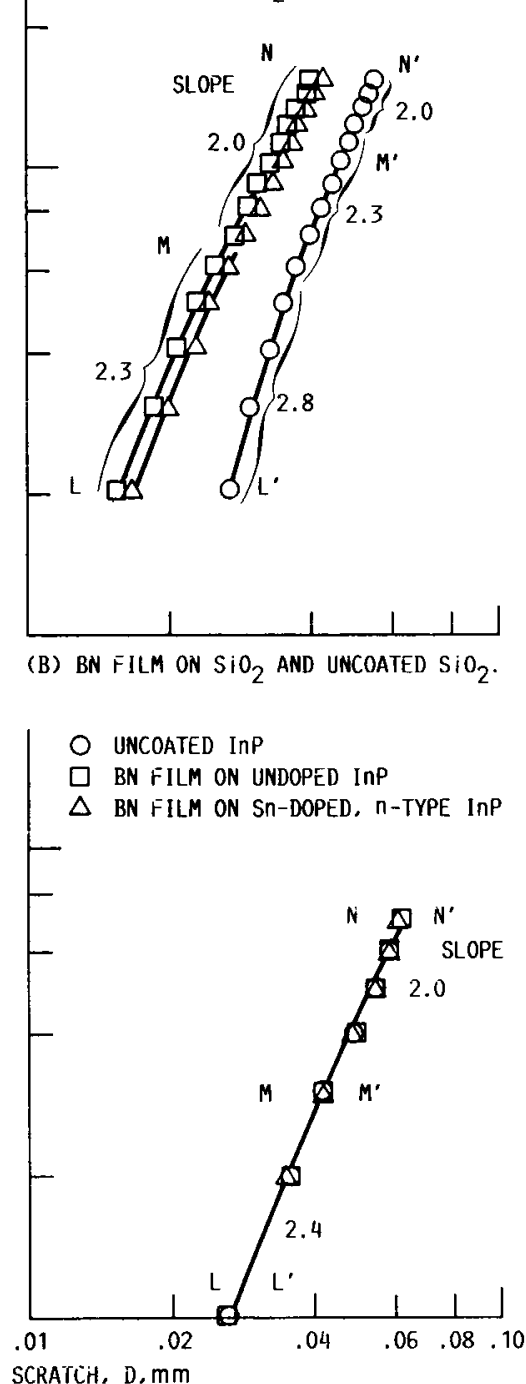

(D) BN FILM ON INP AND UNCOATED InP. FIGURE 5. - SCRATCH WIDTH AS A FUNCTION OF LOAD, SLIDING VELOCITY, $12 \mathrm{~mm} / \mathrm{min}$ : LABORATORY AIR. 


\begin{tabular}{|c|c|c|c|}
\hline $\begin{array}{l}\text { 1. Report No. } \\
\text { NASA TM-89818 }\end{array}$ & 2. Government Accession No. & \multicolumn{2}{|c|}{ 3. Recipient's Catalog No. } \\
\hline \multirow{2}{*}{\multicolumn{2}{|c|}{$\begin{array}{l}\text { 4. Title and Subtitle } \\
\text { Mechanical Strength and Tribological Behavior of } \\
\text { Ion-Beam-Deposited Boron Nitride Films on Non- } \\
\text { metallic Substrates }\end{array}$}} & \multicolumn{2}{|l|}{ 5. Report Date } \\
\hline & & \multicolumn{2}{|c|}{$\begin{array}{l}\text { 6. Performing Organization Code } \\
506-43-11\end{array}$} \\
\hline \multirow{2}{*}{\multicolumn{2}{|c|}{$\begin{array}{l}\text { 7. Author(s) } \\
\text { Kazuhisa Miyoshi, Donald H. Buckley, John J. Pouch, } \\
\text { Samuel A. Alterovitz, and Harold E. Sliney }\end{array}$}} & \multicolumn{2}{|c|}{$\begin{array}{l}\text { 8. Performing Organization Report No. } \\
\text { E- } 3439\end{array}$} \\
\hline & & \multicolumn{2}{|l|}{ 10. Work Unit No. } \\
\hline \multirow{2}{*}{\multicolumn{2}{|c|}{$\begin{array}{l}\text { 9. Performing Organization Name and Address } \\
\text { National Aeronautics and Space Administration } \\
\text { Lewis Research Center } \\
\text { Cleveland, Ohio } 44135\end{array}$}} & \multirow{2}{*}{\multicolumn{2}{|c|}{ 11. Contract or Grant No. }} \\
\hline & & & \\
\hline \multirow{2}{*}{\multicolumn{2}{|c|}{$\begin{array}{l}\text { 12. Sponsoring Agency Name and Address } \\
\text { National Aeronautics and Space Administration } \\
\text { Washington, D.C. } 20546\end{array}$}} & \multicolumn{2}{|c|}{$\begin{array}{l}\text { 13. Type of Report and Period Covered } \\
\text { Technical Memorandum }\end{array}$} \\
\hline & & \multicolumn{2}{|c|}{ 14. Sponsoring Agency Code } \\
\hline \multicolumn{4}{|c|}{$\begin{array}{l}\text { 15. Supplementary Notes } \\
\text { Prepared for the International Conference on Metallurgical Coatings, sponsored } \\
\text { by the American Vacuum Society, San Diego, Callfornia, March 23-27, 1987. } \\
\text { Kazuhisa Miyoshi, John J. Pouch, Samuel A. Alterovitz, and Harold E. Sliney, NASA } \\
\text { Lewis Research Center; Donald H. Buckley, Case Western Reserve University, } \\
\text { Cleveland, Ohio 44106. }\end{array}$} \\
\hline \multicolumn{4}{|c|}{ 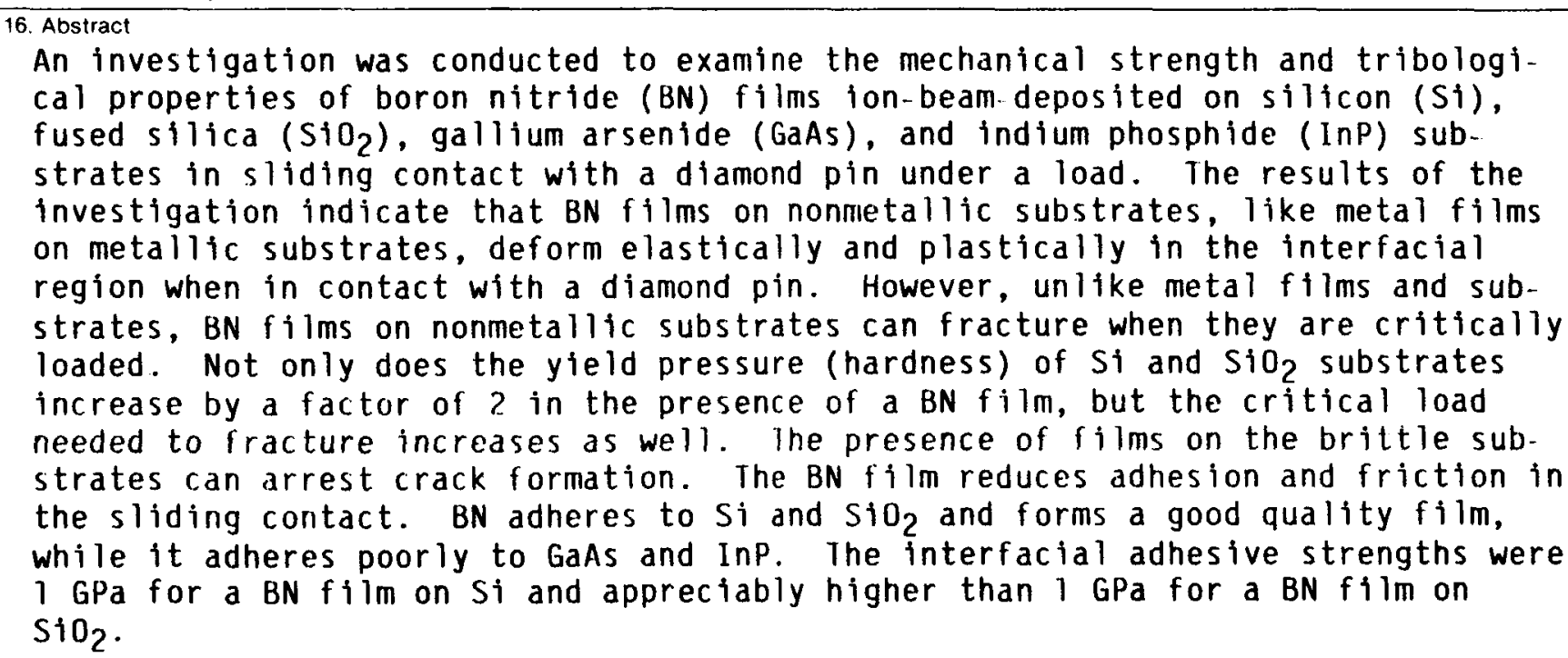 } \\
\hline $\begin{array}{l}\text { 17. Key Words (Suggested by Author(s) } \\
\text { Boron nitride films } \\
\text { Silicon } \\
\text { Silicon dioxide }\end{array}$ & $\begin{array}{l}\text { 18. Distribution } \\
\text { Unc lass } \\
\text { STAR Ca }\end{array}$ & $\begin{array}{l}\text { ent } 27 \\
\text { ry } 27 \text { imited }\end{array}$ & \\
\hline $\begin{array}{l}\text { 19. Security Classif. (of this report) } \\
\text { Unc lass if ied }\end{array}$ & $\begin{array}{l}\text { 0. Security Classif. (of this page) } \\
\text { Unc las If ied }\end{array}$ & 21. No. of pages 21 & 22. Price ${ }^{*} \mathrm{~A} 02$ \\
\hline
\end{tabular}

${ }^{*}$ For saie by the National Technical Information Service, Springfield, Virginia 22161 